\title{
Pharmacological manipulation of Bcl-2 family members to control cell death
}

\author{
Anthony Letai \\ Department of Medical Oncology, Dana-Farber Cancer Institute, Harvard Medical School, Boston, Massachusetts, USA.
}

\begin{abstract}
The commitment to programmed cell death involves complex interactions among pro- and antiapoptotic members of the Bcl-2 family of proteins. The physiological result of a decision by these proteins to undergo cell death is permeabilization of the mitochondrial outer membrane. Pharmacologic manipulation of proteins in this family appears both feasible and efficacious, whether the goal is decreased cell death, as in ischemia of the myocardium or brain, or increased cell death, as in cancer.
\end{abstract}

\section{The Bcl-2 family of proteins}

Bcl-2 was initially cloned from the breakpoint of the $t(14 ; 18)$ chromosomal translocation found in the vast majority of patients with follicular lymphoma, an indolent B cell non-Hodgkin lymphoma (1-3). Expression of Bcl-2 blocked cell death following numerous cell insults $(4,5)$. As a test of its oncogenic function, a minigene bearing the $b c l-2$-immunoglobulin gene fusion, after a period of follicular hyperplasia $(4,5)$, induced lymphoma in transgenic mice (6). While previously characterized oncogenes shared the ability to increase cellular proliferation, Bcl-2 established a new class of oncogenes: inhibitors of programmed cell death.

Since the cloning of $\mathrm{Bcl}-2$, an entire family of proteins related by sequence homology and participation in the control of apoptosis has been identified. Certain proteins share Bcl-2's ability to oppose programmed cell death: Bcl- $\mathrm{x}_{\mathrm{L}}$ (7), Bcl-w (8), Mcl-1 (9), and Bfl-1 (A1) (10). These proteins share sequence homology in 4 $\alpha$-helical Bcl-2 homology (BH) regions, BH1-BH4. Bax (11) and Bak (12), which promote cell death, share only the BH1-BH3 domains. Later, a third class of protein was discovered (13). These include Bid, Bad, Bik, Puma, Noxa, Bmf, and Hrk, which are called "BH3only" proteins and demonstrate homology only in the $\mathrm{BH} 3$ region $(14,15)$. Like Bax and Bak, the proapoptotic $\mathrm{BH} 3$-only proteins require an intact $\mathrm{BH} 3$ domain to promote apoptosis $(14,16)$.

$B c l-2$ proteins control mitochondrial permeabilization. Complex interactions among Bcl-2 family members govern mitochondrial outer membrane permeabilization (MOMP), the final common endpoint for execution of death signals by the Bcl-2 family (17) (Figure 1). Data show that activation of either Bax or Bak is required for MOMP (18-20), suggesting that Bax and Bak are the effectors in the Bcl-2 family most proximal to MOMP. In healthy cells, inactive Bax monomers reside either in the cytosol or in loose association with the mitochondrial outer membrane (21), while monomeric Bak is inserted in the outer membrane. Activation of Bax and/or Bak is accompanied by an allosteric change detectable by conformation-specific antibodies (22-24). Following activation, Bax inserts into the membrane, Bax and Bak homo-oligomerize, and then MOMP occurs $(19,25-27)$. Permeabilization releases proapoptotic factors, including cytochrome c (28), omi/htra2 (29),

Nonstandard abbreviations used: $\mathrm{BH}, \mathrm{Bcl}-2$ homology (domain); MOMP, mitochondrial outer membrane permeabilization.

Conflict of interest: The author has declared that no conflict of interest exists.

Citation for this article: J. Clin. Invest. 115:2648-2655 (2005).

doi:10.1172/JCI26250.
Smac/DIABLO (30, 31), endonuclease G (29), and AIF (32), to the cytosol. Released cytochrome $c$ participates in a holoenzyme complex with Apaf- 1 and caspase- 9 that activates effector caspases by cleavage, resulting in widespread proteolysis. An extrinsic pathway of caspase activation initiated by cell surface death receptor signaling, which operates independently of the mitochondrion and Bcl-2 family members, exists but is beyond the scope of this discussion (33). While oligomers of Bax can form pores in artificial membranes that permit the passage of cytochrome $c(34)$ or highmolecular weight dextran $(35,36)$, it is not clear whether activated Bax and/or Bak independently form pores in vivo, or whether Bax and/or Bak cooperate with other factors (17).

Activation of Bax and/or Bak. The mechanism of Bax and/or Bak activation has been controversial. Recent evidence supports activation of Bax and/or Bak via interaction with select $\mathrm{BH} 3$-only proteins. Bid protein and $\mathrm{BH} 3$ domains from Bid and Bim, but not other $\mathrm{BH}$-only proteins, induce MOMP in a Bax and/or Bak-dependent fashion and induce Bak and Bax oligomerization (19, 37, 38). Induction of these apoptotic changes requires an intact $\mathrm{BH} 3$ domain. The ability of $\mathrm{Bid}, \mathrm{Bim}_{\mathrm{s}}$, or their $\mathrm{BH} 3$ domains to stimulate $\mathrm{Bax}$ oligomerization and pore formation required no other proteins in a defined synthetic liposomal system; this supports a direct interaction $(35,36)$. It has been hypothesized that Bid performs primarily as an inhibitor of Bcl-2. However, a Bid mutant that lacks the ability to interact with Bcl-2 but maintains interaction with Bax is still potently proapoptotic, which suggests that interaction with Bax and/or Bak is important in Bid's function (14).

Complexes of Bid or Bim with Bax or Bak have been difficult, but not impossible, to isolate $(14,39-41)$. Interactions between $\mathrm{BH} 3$ domains and $\mathrm{Bax}$ and/or Bak may be transient, with the $\mathrm{BH} 3$ domain leaving after allosteric activation of Bax and/or Bak in a "hit and run" model. While the BH3 domains of Bid and Bim are necessary for interaction with Bax and Bak, their most efficient presentation to Bax and Bak may require conformational changes, posttranslational modifications, and/or certain isoforms of the entire protein $(39,40,42-45)$. In addition, proteins outside of the Bcl-2 family bind and modulate function of Bax (46-48) and Bak (49).

Bcl-2 blocks Bax and/or Bak-dependent MOMP. Bcl-2 and the related antiapoptotic proteins Bcl- $\mathrm{x}_{\mathrm{L}}, \mathrm{Mcl}-1, \mathrm{Bcl}-\mathrm{w}$, and Bfl-1 inhibit MOMP by binding pro-death family members. Like the proapoptotic multidomain proteins Bax and Bak, the antiapoptotic proteins possess a hydrophobic pocket made from the $\alpha$-helices $\mathrm{BH} 1, \mathrm{BH} 2$, and $\mathrm{BH} 3$, where the hydrophobic face of amphipathic $\alpha$-helical BH3 domains from proapoptotic members binds 

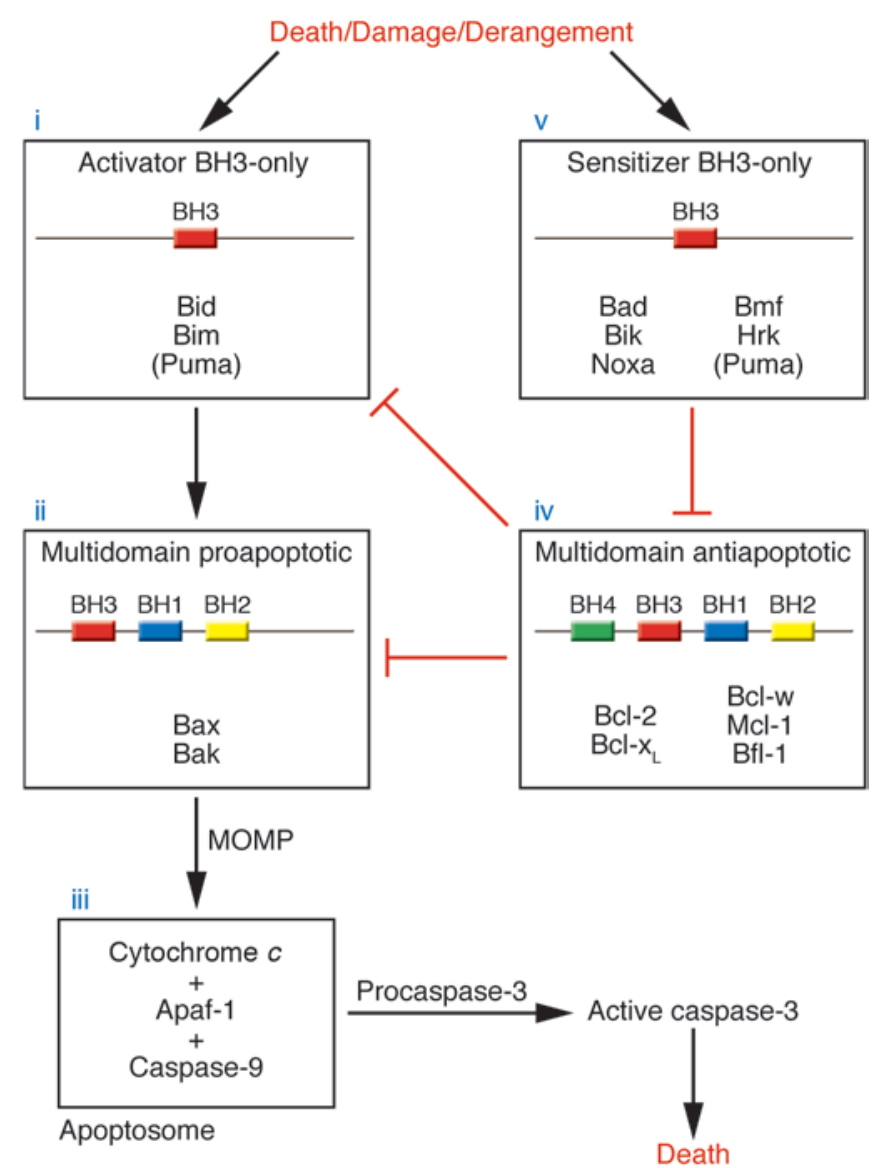

Figure 1

A model of Bcl-2 family member control over programmed cell death. In response to myriad death, damage, or derangement signals, $\mathrm{BH}$ only family members are activated (i). Activator $\mathrm{BH}$-only proteins interact with multidomain proapoptotic Bax and/or Bak (Bax/Bak), inducing their oligomerization (ii) and thus resulting in MOMP, release of cytochrome $c$, apoptosome formation, and caspase activation (iii). $\mathrm{Bcl}-2$ and other multidomain antiapoptotic proteins interrupt the death signal by binding and sequestering activator $\mathrm{BH}$-only family members, and perhaps also Bax/Bak (iv). Bcl-2 antiapoptotic function may be antagonized by the competitive displacement of activator $\mathrm{BH}$-only molecules by sensitizer BH3-only proteins (v).

(50-53). While earlier work focused on the ability of antiapoptotic proteins to bind Bax or Bak, a Bcl- $\mathrm{x}_{\mathrm{L}}$ mutant lacking Bax or Bak binding, but still binding $\mathrm{BH} 3$-only proteins, retained the majority of its antiapoptotic function. This result suggests that binding and sequestration of $\mathrm{BH} 3$-only family members prior to their interaction with Bax and Bak is also an important function of the antiapoptotic proteins $(26,54)$. It is also consistent with the finding that Bcl-2 inhibits apoptosis upstream of Bax and/or Bak conformational change, membrane insertion (in the case of Bax), and oligomerization $(26,37,55,56)$. By binding and sequestering activator $\mathrm{BH} 3$ domains like Bid and Bim, the antiapoptotic proteins inhibit Bax and/or Bak activation and subsequent MOMP.

Antagonism of Bcl-2 by sensitizer BH3-only proteins. While all BH3only proteins are proapoptotic, it is likely that only a subset interacts with Bax and Bak. Using a series of $\mathrm{BH} 3$ peptides, $\mathrm{BH} 3$ domains have been divided into 2 classes: the activators (including Bid and Bim), which can induce Bax and/or Bak oligomerization and MOMP, and the sensitizers, which cannot (37). The ability of p53 to activate Bax suggests there may be other "cryptic" activator molecules outside the Bcl-2 family (57). The sensitizer BH3 domains interact with the antiapoptotic molecules and only indirectly induce Bax and/or Bak activation by competitive displacement of activator $\mathrm{BH} 3$ proteins from the Bcl-2-binding cleft (37). These so-called sensitizer $\mathrm{BH} 3$ domains are thus prototypes of selective inhibitors of the antiapoptotic proteins (see below) (37, 58). Binding of a given $\mathrm{BH} 3$ protein to antiapoptotic proteins is not necessarily promiscuous. For instance, while $\mathrm{BH} 3$ domains from Bid, Bim, and Puma interact with all of the antiapoptotic proteins tested, the remainder interact only with select antiapoptotic partners, suggesting that antiapoptotic proteins have biophysically distinct binding pockets $(36,37,59,60)$. In theory, therefore, individual antiapoptotic family members can be selectively targeted by small molecules that mimic sensitizer $\mathrm{BH} 3$ domain behavior.

BH3-only proteins' response to death stimuli. There remains the question of how BH3-only molecules are triggered to respond to death stimuli (61). In some cases, activation of BH3-only molecules is transcriptional. Noxa and Puma are p53-inducible genes that are transcriptionally induced in response to numerous DNA-damaging agents (62-66). While Bim can be transcriptionally regulated $(67,68)$, its regulation may also depend on cytoskeletal interaction (69) and phosphorylation, which may affect interaction with Bax (40) as well as ubiquitination and proteosomal degradation (70-72). In response to death signals that activate the extrinsic apoptotic pathway, Bid is first cleaved by caspase- $8(42,43)$, and then the new amino terminus is myristoylated to facilitate targeting to the mitochondria (44). Bad is controlled, at least in part, by phosphorylation that mediates its sequestration by cytoplasmic 14-3-3 protein (73). Interaction of Bad with members of the glycolytic pathway suggests a role for Bad in glucose homeostasis (74). It appears that BH3-only family members serve individual but overlapping roles in sensing different types of cellular derangement and communicating these to the core death pathway.

To summarize, conduction of a death signal by the Bcl-2 family members begins with activation of the BH3-only proteins, which act as sentinels of myriad damage signals. Activator $\mathrm{BH} 3$ domains then trigger allosteric activation of Bax and/or Bak, which oligomerize at the mitochondria, inducing MOMP. Proapoptotic factors are released, including cytochrome $c$, which forms a holoenzyme complex with Apaf-1 and caspase- 9 , termed the apoptosome. This complex then catalytically cleaves effector caspases like caspase-3, resulting in widespread proteolysis and commitment to cell death. This pathway can be interrupted by $\mathrm{Bcl}-2$ and related antiapoptotic proteins that bind and sequester the activator $\mathrm{BH} 3$ molecules. Sensitizer BH3-only molecules can further assist the progression of a death signal by competitive displacement of activator $\mathrm{BH} 3$ signals from the Bcl-2 pocket (Figure 1).

Alternative models of the control of apoptosis by Bcl-2 family members exist. In one, Bcl-2 regulates caspases, directly or via an as-yet undiscovered mammalian adaptor $(13,61,75)$. In another, Bcl-2 tonically inhibits oligomerization of a Bax and/or Bak that is ready to induce MOMP without BH3 interaction (76). In a variation of this model, combinations of particular Bcl-2-like proteins must be neutralized by $\mathrm{BH} 3$ ligands to allow Bax and/or Bak activation (60). In another, Bax and/or Bak inhibit a dominantly acting Bcl-2 to induce death (13). However, recent results that emphasize the centrality of Bax and Bak $(18,20)$ and their activation by activator $\mathrm{BH} 3$ domains $(19,26,35-37)$ to MOMP 


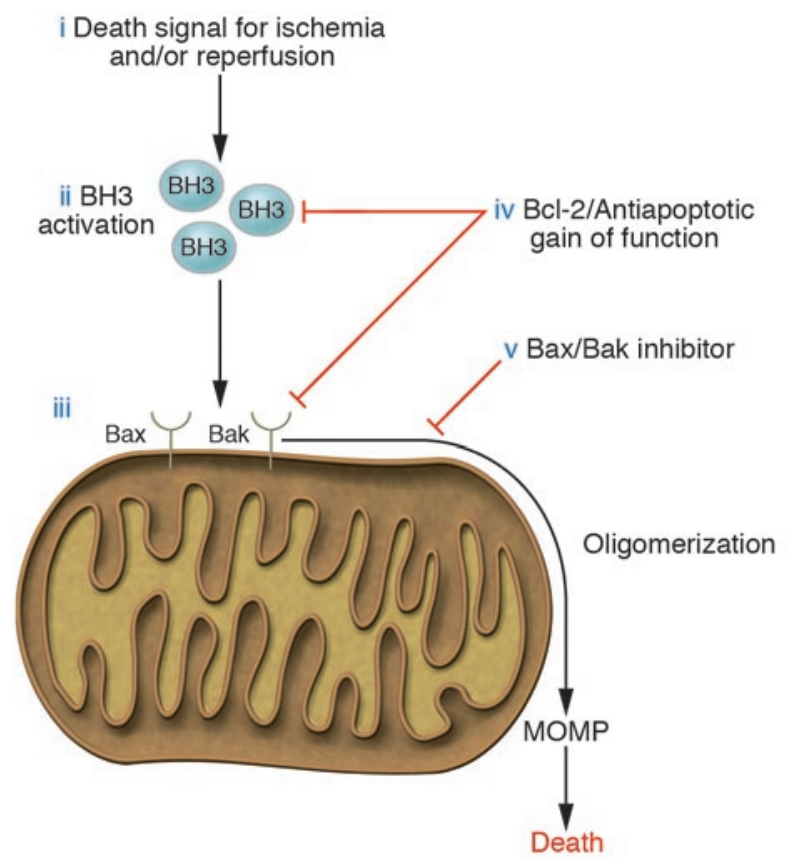

Figure 2

Model of interventions to reduce ischemic and ischemia/reperfusion injury. (i and ii) Following ischemia or ischemia/reperfusion, cell death signals are initiated (i) and conducted to the intrinsic pathway via activated $\mathrm{BH} 3$-only family members (ii). (iii) These $\mathrm{BH} 3$ family members interact with Bax/Bak, inducing oligomerization, MOMP, and commitment to cell death. (iv) Treatment with a viral vector expressing Bcl-2 or other antiapoptotic gain of function might prevent BH3-only activation of Bax/Bak and/or oligomerization of Bax/Bak. (v) Treatment with a Bax/Bak inhibitor might prevent Bax/Bak induction of MOMP.

may call into question the consistency of the above alternatives with mounting experimental data.

\section{Diseases of excessive cell death}

$\mathrm{Bcl}-2$ proteins in acute ischemic diseases. Myocardial ischemia and cerebral ischemia are 2 of the 3 leading causes of death in the developed world. In acute ischemia, sudden loss of blood perfusion, and/or the acute restoration of perfusion, can result in extensive death in the cells of the supplied organ, as in stroke or acute myocardial infarction. In mouse models of cerebral ischemia as well as ischemia/reperfusion injury, loss of proapoptotic Bax or Bid and gain of antiapoptotic Bcl-2 function all reduced infarct size $(77,78)$. In murine models of cardiac ischemia/reperfusion, interference with Bax activation, genetic Bax loss-of-function, or overexpression of $\mathrm{Bcl}-2$ attenuated apoptosis and reduced infarct size, while reduction of $\mathrm{Bcl}-2$ levels via antisense oligonucleotides eliminated adaptive protection from injury (79-82). These studies paint a consistent picture of Bcl-2 family members controlling cell fate during ischemia and reperfusion in the myocardium and in the brain. Inhibition of the intrinsic apoptotic pathway by Bcl-2 overexpression also attenuates the phenotype in animal models of chronic neurodegenerative disease and cardiomyopathy (83-85).

Effective pharmacologic intervention would seem to require either antiapoptotic gain of function or proapoptotic loss of function (Figure 2). In an effort to use the former strategy, viral delivery of a Bcl-2 transgene to cerebral infarcts decreased infarct size (86). Pharmacologic inhibition of Bax has been reported using an assay of Bax-induced
MOMP triggered by recombinant Bid (87). Whether such molecules are safe and effective in vivo remains to be reported. A pentapeptide derived from the Bax-modulating Ku70 protein also inhibits Baxdependent apoptosis (88). In an attempt to block signaling further upstream, a class of small molecules have been described that bind to Bid and inhibit its activation of Bax in mitochondrial assays (89).

In general, the field of therapeutic apoptosis inhibition by manipulation of Bcl-2 family members is young, but mechanistic studies suggest that such a strategy may be useful and feasible. There are many additional chronic degenerative diseases involving apoptosis whose patients might benefit from apoptotic inhibition. Whether therapeutic long-term inhibition of apoptosis might predispose to cancer, as suggested by numerous mouse models, and whether such deleterious side effects might be overcome by pulsatile dosing schedules, remain to be seen.

\section{Diseases characterized by deficient death}

$B c l-2$ family proteins in cancer. The third of the 3 leading causes of mortality in the developed world is cancer, characterized by a failure of programmed cell death (90). While Bcl-2 was initially identified as an oncogene in follicular lymphoma, its expression has been identified in many cancers, including melanoma, myeloma, small-cell lung cancer, and prostate and acute leukemias (58). Expression of other antiapoptotic proteins has been detected in many cancers, including Bfl-1 in diffuse large-cell lymphoma (91), Mcl-1 in myeloma (92), and $\mathrm{Bcl}-\mathrm{x}_{\mathrm{L}}$ in lung adenocarcinoma (93). The oncogenic EBV and human herpes virus-8 (HHV-8; also known as Kaposi sarcoma herpes virus) encode Bcl-2 homologs that oppose cell death from multiple stimuli, analogous to Bcl-2 $(94,95)$. EBV has been implicated in the causation of HIV-related lymphoma, Burkitt lymphoma, nasopharyngeal cancer, and post-transplantation lymphomas, and HHV-8 in the causation of Kaposi sarcoma, Castleman disease, and body cavity lymphomas. Blocking the intrinsic pathway to programmed cell death is apparently important enough in viral infection and perhaps oncogenesis for evolutionary selection for Bcl-2 homologs.

While it seems clear that Bcl-2 can be important in oncogenesis, the essential therapeutic question is whether $\mathrm{Bcl}-2$ is necessary for tumor maintenance. To formally test this question requires the establishing of a tumor that expresses Bcl-2 followed by the induction of loss of Bcl-2 function. To this end, a mouse model of leukemia was generated that contained a Bcl-2 transgene that could be silenced by doxycycline administration (96). To accelerate oncogenesis, mice bearing the conditional $\mathrm{Bcl}-2$ expression system were bred with those bearing the $\mathrm{E} \mu$-myc transgene. Mice coexpressing both c-myc and Bcl-2 developed a B-lymphoblastic leukemia in the first days of life (97). After diagnosis of leukemia, doxycycline was administered to turn off $\mathrm{Bcl}-2$, and a rapid drop in wbc count, from as high as 500,000-1,000,000 cells per microliter to the normal range of 5,000-10,000 cells per microliter, was seen in a matter of days. Bcl-2 downregulation also fostered significantly longer survival (96). This in vivo experiment established the proof of principle that under certain conditions, correction of an apoptotic defect by itself could be lethal to cancer cells, and thus that $\mathrm{Bcl}-2$ was a valid target for cancer therapy. An implication is that $\mathrm{Bcl}-2$ antagonists may have the potential to be efficacious in cancer therapy, even as single agents.

\section{Peptide-based Bcl-2 antagonist compounds}

If $\mathrm{Bcl}-2$ is a valid therapeutic target, how might it be antagonized? Studies suggest that a molecule behaving like a sensitizer $\mathrm{BH} 3$ 

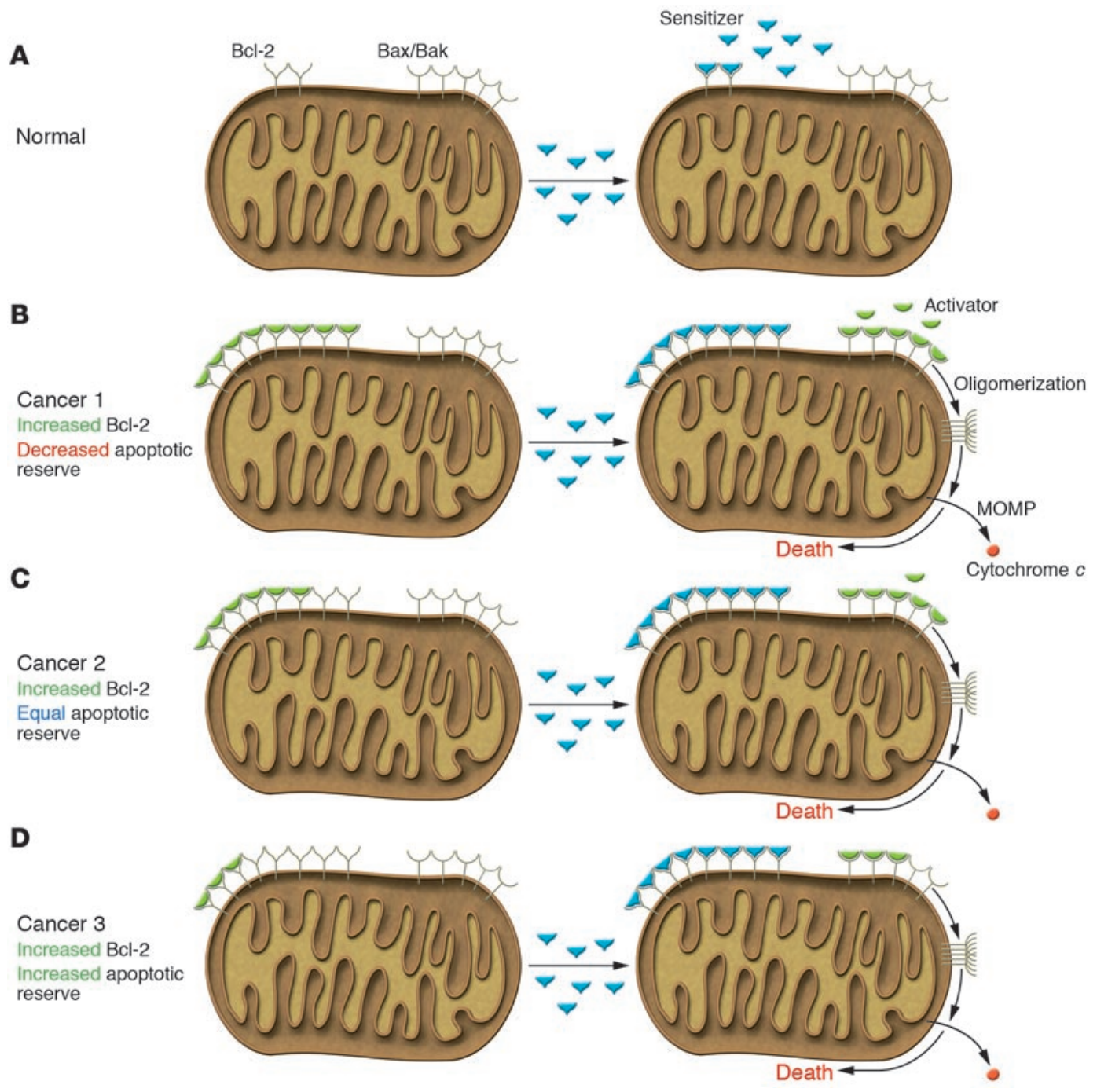

\section{Figure 3}

Model for targeting cancer cells with sensitizer BH3 mimetics. (A) Mitochondrion from a normal cell has some $\mathrm{Bax} / \mathrm{Bak}$ and $\mathrm{Bcl}-2$. Bcl-2 is unoccupied; normal cell behavior is provoking no death signals. (B-D) Mitochondria from cancer cells have equal Bax/Bak and overexpress Bcl-2 in this model. Antiapoptotic reserve is defined as the number of unoccupied antiapoptotic Bcl-2 family member binding pockets per cell. Compared with normal mitochondria, those that overexpress Bcl-2 may provide decreased (B), equal (C), or increased (D) antiapoptotic reserve. Because of genomic instability, oncogene activation, cell cycle checkpoint violation, or perhaps cancer-specific response to cytotoxic chemotherapy, activator $\mathrm{BH} 3$ domains have been triggered and are sequestered by Bcl-2. After exposure to a sensitizer BH3 mimetic (a protein, peptide, or small molecule), activator $\mathrm{BH} 3$ domains are displaced from cancer cells, but not normal cells, activating Bax/Bak and allowing selective cancer cell killing, perhaps even as a single agent. It can be seen why sensitizer mimetics might offer a greater therapeutic window than an activator, as an activator molecule would provide selective killing only at low doses and only for cancer cells in condition 1 (Cancer 1). At higher doses, or if the cancer cells were in condition 2 or 3 , there would be killing of normal and cancer cells. It is unclear whether activator- or sensitizer-type BH3-only family members predominate in the response to conventional chemotherapy agents, and it is likely that a mixture is present. These models also speculate why certain cancers, such as follicular lymphoma and chronic lymphocytic leukemia, despite expressing higher levels of Bcl-2, are more prone to apoptosis than normal cells after DNA-damaging chemotherapy.

domain peptide, binding with high affinity to Bcl-2's pocket, would act as a competitive inhibitor of Bcl-2 function (37), which might induce selective killing of cancer cells (96) (Figure 3). Unmodified $\mathrm{BH} 3$ domain peptides are cell impermeant, so the problem of intracellular delivery must first be overcome. It has been shown that tagging peptides with a poly-D-arginine tag facilitates cell internalization in vitro and in vivo (98). We linked $\mathrm{BH} 3$ peptides from $\mathrm{Bad}$, Bid, and a double point mutant of Bid to an N-terminal poly-Darginine octomer. While r8BidBH3 killed a human leukemia cell line that expresses Bcl-2, the r8BidBH3 double point mutant did not. Furthermore, $10 \mu \mathrm{M}$ of the r8BadBH3 peptide, which caused no apoptosis on its own, increased the killing induced by the r8BidBH3 peptide. These results suggest that the moiety did indeed facilitate internalization, and that an intact $\mathrm{BH} 3$ domain was necessary for killing (37). In a separate study, a 27-amino acid peptide derived from the $\mathrm{BH} 3$ domain of Bad was linked to decanoic acid to facilitate intracellular entry (99). This compound (cpm-1285), but not a peptide bearing a point mutation at a residue necessary 
for $\mathrm{BH} 3$ function, induced apoptosis in a Bcl-2-expressing human myeloid leukemia line, HL-60. Furthermore, immunodeficient mice injected with HL-60 cells survived longer when treated with cpm-1285. Though intriguing, these 2 studies do not conclusively demonstrate the mechanism of action of the peptide derivatives, and it remains possible that some of the cytotoxic effects were independent of direct interaction with Bcl-2 family members.

Highlighting the difficulty in interpreting results of studies using peptides linked to cell internalization moieties, Schimmer and coworkers showed that the $\mathrm{BH} 3$ domain of $\mathrm{Bad}$, linked to the Antennapedia internalization sequence, had considerable off-target toxicity (100). This toxicity was dependent on the presence of an $\alpha$-helix, but independent of the $\mathrm{Bcl}-2$ pathway. The compound was toxic to a wide variety of cells, including yeast, wherein Bcl-2 family members have yet to be identified. Others have demonstrated that $\mathrm{BH} 3$ peptides derived from $\mathrm{Bax}$ and $\mathrm{Bcl}-2$ linked to an Antennapedia internalization sequence induce MOMP and apoptosis (101). These effects are impaired by neither $\mathrm{Bcl}-2$ nor $\mathrm{Bcl}-\mathrm{x}_{\mathrm{L}}$ expression. It may be that these effects are due again to a nonspecific membrane disruption rather than to interaction with the Bcl-2 family pathway. These nonspecific toxicities may be linked to the ability of amphipathic $\alpha$-helices, especially when positively charged, to interact with negatively charged mitochondrial membranes. Such interactions may disrupt the lipid matrix and membrane barrier function of biological membranes independent of Bcl-2 family protein interaction. In summary, interpretation of cell killing by $\mathrm{BH} 3$ peptides linked to internalization moieties is blurred by the possibility of nonspecific killing due to intrinsic biophysical properties. Further pharmaceutical development of such molecules would require considerable attention to reducing this toxicity, which would likely affect normal as well as cancer cells.

Stabilizing the $\alpha$-helical conformation of $\mathrm{BH} 3$ peptides. Others have tried to improve peptide function by stabilizing the $\alpha$-helical conformation of $\mathrm{BH} 3$ peptides, which generally show less than $25 \%$ $\alpha$-helicity in aqueous solution. Grafting a Bak BH3 domain to a helix-stabilizing miniprotein improved affinity for Bcl-2 (102). Synthesizing BH3 peptide analogs with covalent molecular bridges also stabilized the $\alpha$-helical conformation (103). Perhaps the most dramatic example of the potential of $\alpha$-helix stabilization was provided by a Bid BH3 peptide stabilized by an all-hydrocarbon "staple" (104). This modification enhanced $\alpha$-helicity, affinity for Bcl-2, cell entry, protease resistance, and leukemia cell line toxicity in vitro and in vivo. Mice bearing leukemia cell line xenografts enjoyed statistically significant survival improvement of 6 days; treatment duration was limited to 7 days by sufficiency of material. Normal tissues seemed unaffected as measured by histological analysis. It is important to note that this molecule does not behave as a selective $\mathrm{Bcl}-2$ antagonist. As expected, since it was modeled on a Bid peptide previously shown to be an activator (37), the compound was able to directly induce cytochrome $c$ release in a Bak-dependent fashion in vitro. While this molecule behaved as an activator in vitro, it was still able to exploit an apparent therapeutic window between the tumor xenograft and the normal tissues (Figure 3). Subsequent attempts using sensitizer BH3-based compounds may provide an even greater therapeutic window.

\section{Small-molecule Bcl-2 antagonists}

Small molecules that bind to antiapoptotic Bcl-2 family members have been identified using structure-based computer screening. The molecules isolated displaced the $\mathrm{Bak} \mathrm{BH} 3$ peptide from
Bcl-2 with an $\mathrm{IC}_{50}$ of $1-14 \mu \mathrm{M}$. The $K_{\mathrm{d}}$ for the Bak BH3 peptide is approximately $200 \mathrm{nM}$, which suggests that the $K_{\mathrm{d}}$ for binding of these molecules to Bcl-2 would be significantly higher, likely greater than $1 \mu \mathrm{M}$. One of these molecules proved toxic to 4 cell lines tested at concentrations of 10-20 $\mu \mathrm{M}$. Toxicity correlated with amount of Bcl-2 expressed $(105,106)$.

Screens of chemical libraries have also been used. Degterev et al. identified 2 molecules out of 16,320 screened that disrupt a Bcl- $x_{\mathrm{L}} / \mathrm{Bak} \mathrm{BH} 3$ complex (107). Toxicity to a leukemia cell line was observed in the 10- to $90-\mu \mathrm{M}$ range. Tetrocarcin A, derived from Actinomyces, was isolated from a screen of a library of natural products for its ability to counteract Bcl-2 protection of anti-Fas/ cycloheximide-treated HeLa cells at concentrations in the micromolar range (108). Binding assays were not reported. Antimycin A, an antibacterial agent with antitumor properties in experimental systems, was identified from a screen for inhibitors of mitochondrial respiration in mammalian cells (109). Further characterization demonstrated antimycin A's interaction with Bcl-2 and $\mathrm{Bcl}-\mathrm{x}_{\mathrm{L}}$. Increasing cellular levels of $\mathrm{Bcl}-\mathrm{x}_{\mathrm{L}}$ correlated with increasing toxicity of antimycin A, a known inhibitor of electron transport at mitochondrial respiratory chain complex III. A methoxy derivative of antimycin A binds to Bcl-2 with a $K_{\mathrm{d}}$ of $0.82 \mu \mathrm{M}(110)$.

Kutzki et al. used a nonpeptide terphenyl scaffold to design molecules that mimic the binding of $\mathrm{BH} 3$ domains in the hydrophobic pocket of Bcl- $\mathrm{x}_{\mathrm{L}}$, one of which had a $K_{\mathrm{d}}$ as low as $114 \mathrm{nM}$ (111). An investigation of the properties of extracts of green tea revealed, by NMR spectroscopy, that certain polyphenols containing a gallate group were able to bind to $\mathrm{Bcl}-\mathrm{x}_{\mathrm{L}}(112)$. In addition, these compounds displaced a $\mathrm{BH} 3$ domain from $\mathrm{Bcl}-\mathrm{x}_{\mathrm{L}}$ and $\mathrm{Bcl}-2$ in the submicromolar range. A screen of a small library of natural products identified 2 molecules, purpurogallin and gossypol, that inhibit binding of a BH3 domain (resembling that of human $\mathrm{Bad}$ ) to $\mathrm{Bcl}-\mathrm{x}_{\mathrm{L}}$ (113). Chemical modification of purpurogallin did not lower the $\mathrm{IC}_{50}$ of peptide displacement below $2.2 \mu \mathrm{M}$ of the parental compound. A racemic mixture of the $(+)$ and (-) isomers of gossypol displaced the $\mathrm{BH} 3$ peptide with an $\mathrm{IC}_{50}$ of $0.5 \mu \mathrm{M}$. The fact that gossypol kills HeLa cells less efficiently when they overexpress $\mathrm{Bcl}-\mathrm{x}_{\mathrm{L}}$ is taken as evidence that gossypol targets $\mathrm{Bcl}-\mathrm{x}_{\mathrm{L}}$. Removal of 2 aldehyde groups from gossypol was performed after molecular modeling suggested that this might reduce steric hindrance in binding the hydrophobic pocket of Bcl- $\mathrm{x}_{\mathrm{L}}$ (114). The sonamed apogossypol, however, demonstrated inferior binding to Bcl-2 family members.

\section{Validation of antagonists of antiapoptotic family members}

Many of the studies cited above provide solid evidence that a particular molecule binds with reasonable affinity ( $K_{\mathrm{d}}$ roughly $1 \mu \mathrm{M}$ or less) to $\mathrm{Bcl}-2$ or $\mathrm{Bcl}-\mathrm{x}_{\mathrm{L}}$. Mechanistic evidence demonstrating that killing of living cells depends on specific targeting of $\mathrm{Bcl}-2$ or $\mathrm{Bcl}-\mathrm{x}_{\mathrm{L}}$ is generally lacking, however. Studies lacking a defined Bcl-2-dependent system can be difficult to interpret. This is evident in that different studies have been interpreted to show, variously, that (a) the compound is working specifically via $\mathrm{Bcl}-2$ or $\mathrm{Bcl}-\mathrm{x}_{\mathrm{L}}$ inhibition because cells expressing Bcl-2 or Bcl- $\mathrm{x}_{\mathrm{L}}$ are more sensitive $(106,109)$ or $(\mathrm{b})$ the compound is working specifically via $\mathrm{Bcl}-2$ or $\mathrm{Bcl}-\mathrm{x}_{\mathrm{L}}$ inhibition because cells expressing $\mathrm{Bcl}-2$ or $\mathrm{Bcl}-\mathrm{x}_{\mathrm{L}}$ are less sensitive to compound treatment (113). While, in fact, either statement is potentially true of selective Bcl-2 inhibition, detailed, controlled understanding of the cellular context is necessary for proper interpretation. 
The essential problem of assaying Bcl-2 function is that the endpoint of cell death is shared by the targeting of countless cellular pathways, and Bcl-2 lacks quantifiable enzymatic activity. Some researchers find the use of defined Bcl-2-dependent systems indispensable for demonstration of specific Bcl-2 inhibition. One useful example is the murine FL5.12 cell line, which is dependent on IL-3 for survival. Programmed cell death following IL-3 removal is prevented by overexpression of a human $\mathrm{Bcl}-2$ transgene (5). Therefore, the IL-3-starved Bcl-2-overexpressing FL5.12 cell is a model of dependence on Bcl-2 for survival. A compound working selectively via Bcl-2 inhibition should kill IL-3-starved, but not unstarved, Bcl-2-overexpressing cells; critically, the parental FL5.12 cells should also be spared death following treatment (115). Testing can be extended to isolated mitochondria, with cytochrome $c$ release as the readout of MOMP (37). Peptides derived from the $\mathrm{BH} 3$ domains of Bad or Noxa, while cell impermeant, may then be used as validated positive and negative controls of Bcl-2 antagonism. Insensitivity of mitochondria and cells deficient in both Bax and Bak to compound treatment would provide further support for the test compound's operating through the mitochondrial pathway controlled by Bcl-2 family members $(20,37)$.

\section{Bcl-2 antagonists in clinical development}

Antisense strategy. Oblimersen (Genasense; Genta Inc.) is an 18-mer phosphorothioated oligonucleotide directed against the first 6 codons of the human Bcl-2 open reading frame (116). It has advanced through clinical trials with tolerable side effects, mainly thrombocytopenia, fatigue, back pain, weight loss, and dehydration (117). Demonstration of efficacy has been difficult. In a randomized phase III study of patients with metastatic melanoma, treatment with dacarbazine and oblimersen showed no significant benefit in overall survival compared with dacarbazine alone (274 vs. 238 days, $P=0.18)$. There was significant benefit in progressionfree survival ( 74 vs. 49 days, $P=0.0003$ ), but since overall survival was the primary endpoint, an FDA panel stated that the clinical benefit was inadequate to offset the increased toxicity.

In chronic lymphocytic leukemia, despite early problems with a cytokine release syndrome, a phase III trial showed improved major responses (complete response plus nodular partial responses) in patients treated with oblimersen, fludarabine, and cyclophosphamide compared with those treated with fludarabine and cyclophosphamide alone ( $16 \%$ vs. $7 \%, P=0.039)$. A phase III trial in myeloma in which oblimersen plus high dexamethasone was compared with dexamethasone alone failed to meet its primary endpoint, which was time to disease progression. Furthermore, in another myeloma trial, response to oblimersen did not correlate with reduction in $\mathrm{Bcl}-2$ protein levels.

In general, efficacy has not been overwhelming, and FDA approval of oblimersen as an anticancer agent remains in doubt. There are several reasons why this does not necessarily augur poorly for strategies targeting Bcl-2 in general. First, the cellular effects of the lowering of Bcl-2 levels by antisense oligonucelotides are likely very differ- ent from the cellular effects of functional antagonism of the protein and include possible undesirable coregulation of other Bcl-2 family members (118). Furthermore, the reductions in Bcl-2 protein levels tend to be modest, in the $10-50 \%$ range. Finally, oblimersen likely has immune system effects via its $2 \mathrm{CpG}$ dinucleotides. While potentially beneficial, these may well limit its maximum tolerated dose, because of side effects including cytokine release syndrome.

Competitive antagonists of $\mathrm{Bcl}-2$. Other compounds in clinical development are small molecules that bind the hydrophobic pocket of Bcl-2 analogously to our sensitizer $\mathrm{BH} 3$ peptides. The biotechnology company Gemin X has isolated a compound (GX01) from a high-throughput screen of chemical libraries, reported (in abstract form) to possess the ability to bind $\mathrm{Bcl}-2$ and $\mathrm{Bcl}-\mathrm{x}_{\mathrm{L}}$ and displace $\mathrm{BH} 3$ domains from their binding pockets (119). There is little public information regarding its mechanism of action in living cells. It is currently in phase I clinical trials in both chronic lymphocytic leukemia (at UCSD) and solid tumors (at Georgetown University). Ascenta Therapeutics has an orally administered gossypol derivative in a phase I cancer trial. There is little publicly available information on this compound.

Using a strategy of high-throughput screening combined with iterative modulation of chemical structure based on NMR, Abbott Laboratories has developed compounds reported to displace $\mathrm{BH} 3$ domains from $\mathrm{Bcl}-2, \mathrm{Bcl}-\mathrm{x}_{\mathrm{L}}$, and $\mathrm{Bcl}-\mathrm{w}$ with an $\mathrm{IC}_{50}$ of no more than $1 \mathrm{nM}$. One lead molecule, ABT-737, is reported to have significant activity in mouse xenograft models of lung cancer and lymphoma (115). This series of compounds has not yet entered clinical trials.

\section{Conclusions}

Our current understanding of the mechanisms by which Bcl-2 family members control commitment to cell death gives good theoretical backing to strategies aimed at manipulating this system for clinical benefit. Studies presented above support both the feasibility and the utility of targeting pro- and antiapoptotic proteins. Clinical trials of $\mathrm{Bcl}-2$ antagonists are under way, with more to be expected in the next few years. Given that different antiapoptotic proteins demonstrate distinct binding specificities, it seems likely that in the future the other antiapoptotic proteins might also be individually targeted pharmacologically. Twenty years after the cloning of Bcl-2, we are starting to reap the translational harvest of much fundamental research into the molecular mechanisms controlling apoptosis.

\section{Acknowledgments}

A. Letai is supported by NIH grant K08 CA10254, the Claudia Adams Barr Foundation, and the Richard and Susan Smith Family Foundation (Chestnut Hill, Massachusetts, USA).

Address correspondence to: Anthony Letai, Dana 530B, Department of Medical Oncology, Dana-Farber Cancer Institute, Harvard Medical School, 44 Binney Street, Boston, Massachusetts 02115, USA. Phone: (617) 632-2348; Fax: (617) 582-8160; E-mail: anthony_letai@dfci.harvard.edu.
1. Tsujimoto, Y., Cossman, J., Jaffe, E., and Croce, C.M. 1985. Involvement of the bcl-2 gene in human follicular lymphoma. Science. 228:1440-1443.

2. Cleary, M.L., and Sklar, J. 1985. Nucleotide sequence of a $\mathrm{t}(14 ; 18)$ chromosomal breakpoint in follicular lymphoma and demonstration of a breakpoint-cluster region near a transcriptionally active locus on chromosome 18. Proc. Natl. Acad. Sci. U. S. A. 82:7439-7443.
3. Bakhshi, A., et al. 1985. Cloning the chromosomal breakpoint of $t(14 ; 18)$ human lymphomas: clustering around $\mathrm{JH}$ on chromosome 14 and near a transcriptional unit on 18. Cell. 41:899-906.

4. McDonnell, T.J., et al. 1989. bcl-2-immunoglobulin transgenic mice demonstrate extended B cell survival and follicular lymphoproliferation. Cell. 57:79-88.

5. Vaux, D.L., Cory, S., and Adams, J.M. 1988. Bcl-2 gene promotes haemopoietic cell survival and cooperates with c-myc to immortalize pre-B cells. Nature. 335:440-442.

6. McDonnell, T.J., and Korsmeyer, S.J. 1991. Progression from lymphoid hyperplasia to high-grade malignant lymphoma in mice transgenic for the $\mathrm{t}(14 ; 18)$. Nature. 349:254-256.

7. Boise, L.H., et al. 1993. bcl-x, a bcl-2-related gene that functions as a dominant regulator of apop- 
totic cell death. Cell. 74:597-608.

8. Gibson, L., et al. 1996. bcl-w, a novel member of the bcl-2 family, promotes cell survival. Oncogene. 13:665-675.

9. Kozopas, K.M., Yang, T., Buchan, H.L., Zhou, P., and Craig, R.W. 1993. MCL1, a gene expressed in programmed myeloid cell differentiation, has sequence similarity to BCL2. Proc. Natl. Acad. Sci. U. S. A. 90:3516-3520.

10. Choi, S.S., et al. 1995. A novel Bcl-2 related gene, Bfl-1, is overexpressed in stomach cancer and preferentially expressed in bone marrow. Oncogene. 11:1693-1698.

11. Oltvai, Z.N., Milliman, C.L., and Korsmeyer, S.J. 1993. Bcl-2 heterodimerizes in vivo with a conserved homolog, Bax, that accelerates programmed cell death. Cell. 74:609-619.

12. Chittenden, T., et al. 1995. Induction of apoptosis by the Bcl-2 homologue Bak. Nature. 374:733-736.

13. Huang, D.C., and Strasser, A. 2000. BH3-only proteins-essential initiators of apoptotic cell death. Cell. 103:839-842.

14. Wang, K., Yin, X.M., Chao, D.T., Milliman, C.L., and Korsmeyer, S.J. 1996. BID: a novel BH3 domainonly death agonist. Genes Dev. 10:2859-2869.

15. Boyd, J.M., et al. 1995. Bik, a novel death-inducing protein shares a distinct sequence motif with Bcl-2 family proteins and interacts with viral and cellular survival-promoting proteins. Oncogene. 11:1921-1928.

16. Chittenden, T., et al. 1995. A conserved domain in $\mathrm{Bak}$, distinct from $\mathrm{BH} 1$ and $\mathrm{BH} 2$, mediates cell death and protein binding functions. $E M B O J$. 14:5589-5596.

17. Green, D.R., and Kroemer, G. 2004. The pathophysiology of mitochondrial cell death. Science. 305:626-629.

18. Lindsten, T., et al. 2000. The combined functions of proapoptotic Bcl-2 family members Bak and Bax are essential for normal development of multiple tissues. Mol. Cell. 6:1389-1399.

19. Wei, M.C., et al. 2000. tBID, a membrane-targeted death ligand, oligomerizes BAK to release cytochrome c. Genes Dev. 14:2060-2071.

20. Wei, M.C., et al. 2001. Proapoptotic BAX and BAK: a requisite gateway to mitochondrial dysfunction and death. Science. 292:727-730.

21. Suzuki, M., Youle, R.J., and Tjandra, N. 2000. Structure of Bax: coregulation of dimer formation and intracellular localization. Cell. 103:645-654.

22. Griffiths, G.J., et al. 1999. Cell damage-induced conformational changes of the pro-apoptotic protein Bak in vivo precede the onset of apoptosis. J. Cell Biol. 144:903-914.

23. Desagher, S., et al. 1999. Bid-induced conformational change of Bax is responsible for mitochondrial cytochrome c release during apoptosis. J. Cell Biol. 144:891-901.

24. Hsu, Y.T., and Youle, R.J. 1997. Nonionic detergents induce dimerization among members of the $\mathrm{Bcl}-2$ family. J. Biol. Chem. 272:13829-13834

25. Wolter, K.G., et al. 1997. Movement of Bax from the cytosol to mitochondria during apoptosis. J. Cell Biol. 139:1281-1292.

26. Cheng, E.H., et al. 2001. BCL-2, Bcl-X(L) sequester $\mathrm{BH} 3$ domain-only molecules preventing BAX-and BAK-mediated mitochondrial apoptosis. Mol. Cell. 8:705-711.

27. Gross, A., Jockel, J., Wei, M.C., and Korsmeyer, S.J. 1998. Enforced dimerization of BAX results in its translocation, mitochondrial dysfunction and apoptosis. EMBO J. 17:3878-3885.

28. Liu, X., Kim, C.N., Yang, J., Jemmerson, R., and Wang, X. 1996. Induction of apoptotic program in cell-free extracts: requirement for dATP and cytochrome c. Cell. 86:147-157.

29. Li, L.Y., Luo, X., and Wang, X. 2001. Endonuclease $\mathrm{G}$ is an apoptotic DNase when released from mito- chondria. Nature. 412:95-99.

30. Du, C., Fang, M., Li, Y., Li, L., and Wang, X. 2000. Smac, a mitochondrial protein that promotes cytochrome c-dependent caspase activation by eliminating IAP inhibition. Cell. 102:33-42.

31. Verhagen, A.M., et al. 2000. Identification of DIA$\mathrm{BLO}$, a mammalian protein that promotes apoptosis by binding to and antagonizing IAP proteins. Cell. 102:43-53.

32. Susin, S.A., et al. 1999. Molecular characterization of mitochondrial apoptosis-inducing factor. Nature. 397:441-446.

33. Danial, N.N., and Korsmeyer, S.J. 2004. Cell death: critical control points [review]. Cell. 116:205-219.

34. Saito, M., Korsmeyer, S.J., and Schlesinger, P.H. 2000. BAX-dependent transport of cytochrome c reconstituted in pure liposomes. Nat. Cell Biol. 2:553-555.

35. Kuwana, T., et al. 2002. Bid, Bax, and lipids cooperate to form supramolecular openings in the outer mitochondrial membrane. Cell. 111:331-342.

36. Kuwana, T., et al. 2005. BH3 domains of BH3only proteins differentially regulate Bax-mediated mitochondrial membrane permeabilization both directly and indirectly. Mol. Cell. 17:525-535.

37. Letai, A., et al. 2002. Distinct BH3 domains either sensitize or activate mitochondrial apoptosis, serving as prototype cancer therapeutics. Cancer Cell. 2:183-192

38. Eskes, R., Desagher, S., Antonsson, B., and Martinou, J.C. 2000. Bid induces the oligomerization and insertion of Bax into the outer mitochondrial membrane. Mol. Cell. Biol. 20:929-935.

39. Marani, M., Tenev, T., Hancock, D., Downward, J., and Lemoine, N.R. 2002. Identification of novel isoforms of the $\mathrm{BH} 3$ domain protein Bim which directly activate Bax to trigger apoptosis. Mol. Cell. Biol. 22:3577-3589.

40. Harada, H., Quearry, B., Ruiz-Vela, A., and Korsmeyer, S.J. 2004. Survival factor-induced extracellular signal-regulated kinase phosphorylates BIM, inhibiting its association with BAX and proapoptotic activity. Proc. Natl. Acad. Sci. U. S. A. 101:15313-15317.

41. Cartron, P.F., et al. 2004. The first alpha helix of Bax plays a necessary role in its ligand-induced activation by the $\mathrm{BH} 3$-only proteins Bid and PUMA. Mol. Cell. 16:807-818.

42. Li, H., Zhu, H., Xu, C.J., and Yuan, J. 1998. Cleavage of BID by caspase 8 mediates the mitochondrial damage in the Fas pathway of apoptosis. Cell. 94:491-501.

43. Luo, X., Budihardjo, I., Zou, H., Slaughter, C., and Wang, X. 1998. Bid, a Bcl2 interacting protein, mediates cytochrome $\mathrm{c}$ release from mitochondria in response to activation of cell surface death receptors. Cell. 94:481-490.

44. Zha, J., Weiler, S., Oh, K.J., Wei, M.C., and Korsmeyer, S.J. 2000. Posttranslational N-myristoylation of BID as a molecular switch for targeting mitochondria and apoptosis. Science. 290:1761-1765.

45. Terradillos, O., Montessuit, S., Huang, D.C., and Martinou, J.C. 2002. Direct addition of BimL to mitochondria does not lead to cytochrome c release. FEBS Lett. 522:29-34.

46. Sawada, M., et al. 2003. Ku70 suppresses the apoptotic translocation of Bax to mitochondria. Nat. Cell Biol. 5:320-329.

47. Guo, B., et al. 2003. Humanin peptide suppresses apoptosis by interfering with Bax activation. Nature. 423:456-461.

48. Ohtsuka, T., et al. 2004. ASC is a Bax adaptor and regulates the p53-Bax mitochondrial apoptosis pathway. Nat. Cell Biol. 6:121-128.

49. Cheng, E.H., Sheiko, T.V., Fisher, J.K., Craigen, W.J., and Korsmeyer, S.J. 2003. VDAC2 inhibits BAK activation and mitochondrial apoptosis. Science. 301:513-517.
50. Muchmore, S.W., et al. 1996. X-ray and NMR structure of human Bcl-xL, an inhibitor of programmed cell death. Nature. 381:335-341.

51. Sattler, M., et al. 1997. Structure of Bcl-xL-Bak peptide complex: recognition between regulators of apoptosis. Science. 275:983-986.

52. Petros, A.M., et al. 2001. Solution structure of the antiapoptotic protein bcl-2. Proc. Natl. Acad. Sci. U. S. A. 98:3012-3017.

53. Petros, A.M., et al. 2000. Rationale for Bcl-xL/ Bad peptide complex formation from structure, mutagenesis, and biophysical studies. Protein Sci. 9:2528-2534.

54. Cheng, E.H., Levine, B., Boise, L.H., Thompson, C.B., and Hardwick, J.M. 1996. Bax-independent inhibition of apoptosis by Bcl-XL. Nature. 379:554-556.

55. Murphy, K.M., Streips, U.N., and Lock, R.B. 2000. Bcl-2 inhibits a Fas-induced conformational change in the Bax $\mathrm{N}$ terminus and Bax mitochondrial translocation. J. Biol. Chem. 275:17225-17228.

56. Mikhailov, V., et al. 2001. Bcl-2 prevents Bax oligomerization in the mitochondrial outer membrane. J. Biol. Chem. 276:18361-18374.

57. Chipuk, J.E., et al. 2004. Direct activation of Bax by p53 mediates mitochondrial membrane permeabilization and apoptosis. Science. 303:1010-1014.

58. Letai, A. 2003. BH3 domains as BCL-2 inhibitors: prototype cancer therapeutics. Expert Opin. Biol. Ther. 3:293-304.

59. Opferman, J.T., et al. 2003. Development and maintenance of $\mathrm{B}$ and $\mathrm{T}$ lymphocytes requires antiapoptotic MCL-1. Nature. 426:671-676.

60. Chen, L., et al. 2005. Differential targeting of prosurvival Bcl-2 proteins by their $\mathrm{BH} 3$-only ligands allows complementary apoptotic function. Mol. Cell. 17:393-403.

61. Puthalakath, H., and Strasser, A. 2002. Keeping killers on a tight leash: transcriptional and posttranslational control of the pro-apoptotic activity of BH3-only proteins [review]. Cell Death Differ. 9:505-512.

62. Oda, E., et al. 2000. Noxa, a BH3-only member of the Bcl-2 family and candidate mediator of p53induced apoptosis. Science. 288:1053-1058.

63. Nakano, K., and Vousden, K.H. 2001. PUMA, a novel proapoptotic gene, is induced by $553 . \mathrm{Mol}$. Cell. 7:683-694.

64. Yu, J., Zhang, L., Hwang, P.M., Kinzler, K.W., and Vogelstein, B. 2001. PUMA induces the rapid apoptosis of colorectal cancer cells. Mol. Cell. 7:673-682.

65. Han, J., et al. 2001. Expression of bbc3, a pro-apoptotic BH3-only gene, is regulated by diverse cell death and survival signals. Proc. Natl. Acad. Sci.U.S. A. 98:11318-11323

66. Jeffers, J.R., et al. 2003. Puma is an essential mediator of p53-dependent and -independent apoptotic pathways. Cancer Cell. 4:321-328.

67. Dijkers, P.F., Medema, R.H., Lammers, J.W., Koenderman, L., and Coffer, P.J. 2000. Expression of the pro-apoptotic Bcl-2 family member Bim is regulated by the forkhead transcription factor FKHR-L1. Curr. Biol. 10:1201-1204.

68. Putcha, G.V., et al. 2001. Induction of BIM, a proapoptotic BH3-only BCL-2 family member, is critical for neuronal apoptosis. Neuron. 29:615-628.

69. Puthalakath, H., Huang, D.C., O’Reilly, L.A., King, S.M., and Strasser, A. 1999. The proapoptotic activity of the Bcl-2 family member Bim is regulated by interaction with the dynein motor complex. Mol. Cell. 3:287-296.

70. Tan, T.T., et al. 2005. Key roles of BIM-driven apoptosis in epithelial tumors and rational chemotherapy. Cancer Cell. 7:227-238.

71. Ley, R., et al. 2004. Extracellular signal-regulated kinases $1 / 2$ are serum-stimulated "Bim(EL) kinases" that bind to the BH3-only protein Bim(EL) causing its phosphorylation and turnover. J. Biol. Chem. 279:8837-8847. 
72. Luciano, F., et al. 2003. Phosphorylation of Bim-EL by Erk $1 / 2$ on serine 69 promotes its degradation via the proteasome pathway and regulates its proapoptotic function. Oncogene. 22:6785-6793.

73. Zha, J., Harada, H., Yang, E., Jockel, J., and Korsmeyer, S.J. 1996. Serine phosphorylation of death agonist BAD in response to survival factor results in binding to 14-3-3 not Bcl-X(L). Cell. 87:619-628.

74. Danial, N.N., et al. 2003. BAD and glucokinase reside in a mitochondrial complex that integrates glycolysis and apoptosis. Nature. 424:952-956.

75. Cory, S., and Adams, J.M. 2002. The Bcl2 family: regulators of the cellular life-or-death switch [review]. Nat. Rev. Cancer. 2:647-656.

76. Adams, J.M. 2003. Ways of dying: multiple pathways to apoptosis [review]. Genes Dev. 17:2481-2495.

77. Gibson, M.E., et al. 2001. BAX contributes to apoptotic-like death following neonatal hypoxia-ischemia: evidence for distinct apoptosis pathways. Mol. Med. 7:644-655.

78. Plesnila, N., et al. 2001. BID mediates neuronal cell death after oxygen/glucose deprivation and focal cerebral ischemia. Proc. Natl. Acad. Sci. U. S. A. 98:15318-15323.

79. Gustafsson, A.B., Tsai, J.G., Logue, S.E., Crow, M.T., and Gottlieb, R.A. 2004. Apoptosis repressor with caspase recruitment domain protects against cell death by interfering with Bax activation. J. Biol. Chem. 279:21233-21238.

80. Chen, Z., Chua, C.C., Ho, Y.S., Hamdy, R.C., and Chua, B.H. 2001. Overexpression of Bcl-2 attenuates apoptosis and protects against myocardial I/R injury in transgenic mice. Am. J. Physiol. Heart Circ. Physiol. 280:H2313-H2320.

81. Hochhauser, E., et al. 2003. Bax ablation protects against myocardial ischemia-reperfusion injury in transgenic mice. Am. J. Physiol. Heart Circ. Physiol. 284:H2351-H2359.

82. Hattori, R., et al. 2001. An essential role of the antioxidant gene $\mathrm{Bcl}-2$ in myocardial adaptation to ischemia: an insight with antisense Bcl-2 therapy. Antioxid. Redox Signal. 3:403-413.

83. Azzouz, M., et al. 2000. Increased motoneuron survival and improved neuromuscular function in transgenic ALS mice after intraspinal injection of an adeno-associated virus encoding $\mathrm{Bcl}-2$. Hum. Mol. Genet. 9:803-811.

84. Kostic, V., Jackson-Lewis, V., de Bilbao, F., DuboisDauphin, M., and Przedborski, S. 1997. Bcl-2: prolonging life in a transgenic mouse model of familial amyotrophic lateral sclerosis. Science. 277:559-562.

85. Weisleder, N., Taffet, G.E., and Capetanaki, Y. 2004 $\mathrm{Bcl}-2$ overexpression corrects mitochondrial defects and ameliorates inherited desmin null cardiomyopathy. Proc. Natl. Acad. Sci. U. S. A. 101:769-774.

86. Lawrence, M.S., Ho, D.Y., Sun, G.H., Steinberg, G.K., and Sapolsky, R.M. 1996. Overexpression of $\mathrm{Bcl}-2$ with herpes simplex virus vectors protects CNS neurons against neurological insults in vitro and in vivo. J. Neurosci. 16:486-496.
87. Bombrun, A., et al. 2003. 3,6-Dibromocarbazole piperazine derivatives of 2-propanol as first inhibitors of cytochrome c release via Bax channel modulation. J. Med. Chem. 46:4365-4368.

88. Sawada, M., Hayes, P., and Matsuyama, S. 2003. Cytoprotective membrane-permeable peptides designed from the Bax-binding domain of Ku70. Nat. Cell Biol. 5:352-357.

89. Becattini, B., et al. 2004. Targeting apoptosis via chemical design: inhibition of bid-induced cell death by small organic molecules. Chem. Biol. 11:1107-1117.

90. Green, D.R., and Evan, G.I. 2002. A matter of life and death. Cancer Cell. 1:19-30.

91. Shipp, M.A., et al. 2002. Diffuse large B-cell lymphoma outcome prediction by gene-expression profiling and supervised machine learning. Nat. Med. 8:68-74.

92. Derenne, S., et al. 2002. Antisense strategy shows that $\mathrm{Mcl}-1$ rather than $\mathrm{Bcl}-2$ or $\mathrm{Bcl}-\mathrm{x}(\mathrm{L})$ is an essential survival protein of human myeloma cells. Blood. 100:194-199.

93. Berrieman, H.K., et al. 2005. The expression of Bcl-2 family proteins differs between nonsmall cell lung carcinoma subtypes. Cancer. 103:1415-1419.

94. Henderson, S., et al. 1993. Epstein-Barr virus-coded BHRF1 protein, a viral homologue of Bcl-2, protects human B cells from programmed cell death. Proc. Natl. Acad. Sci. U. S. A. 90:8479-8483.

95. Cheng, E.H., et al. 1997. A Bcl-2 homolog encoded by Kaposi sarcoma-associated virus, human herpesvirus 8 , inhibits apoptosis but does not heterodimerize with Bax or Bak. Proc. Natl. Acad. Sci. U. S. A. 94:690-694.

96. Letai, A., Beard, C., Sorcinelli, M., and Korsmeyer, S.J. 2004. Anti-apoptotic BCL-2 is required for maintenance of a model leukemia. Cancer Cell. 6:241-249.

97. Strasser, A., Harris, A.W., Bath, M.L., and Cory, S. 1990. Novel primitive lymphoid tumours induced in transgenic mice by cooperation between myc and bcl-2. Nature. 348:331-333.

98. Rothbard, J.B., et al. 2000. Conjugation of arginine oligomers to cyclosporin A facilitates topical delivery and inhibition of inflammation. Nat. Med. 6:1253-1257.

99. Wang, J.L., et al. 2000. Cell permeable Bcl-2 binding peptides: a chemical approach to apoptosis induction in tumor cells. Cancer Res. 60:1498-1502.

100.Schimmer, A.D., et al. 2001. The BH3 domain of BAD fused to the Antennapedia peptide induces apoptosis via its alpha helical structure and independent of Bcl-2. Cell Death Differ. 8:725-733.

101.Vieira, H.L., et al. 2000. Permeabilization of the mitochondrial inner membrane during apoptosis: impact of the adenine nucleotide translocator. Cell Death Differ. 7:1146-1154.

102.Chin, J.W., and Schepartz, A. 2001. Design and evolution of a miniature Bcl-2 binding protein. Angew. Chem. Int. Ed. Engl. 40:3806-3809.

103.Yang, B., Liu, D., and Huang, Z. 2004. Synthesis and helical structure of lactam bridged $\mathrm{BH} 3$ peptides derived from pro-apoptotic Bcl-2 family proteins. Bioorg. Med. Chem. Lett. 14:1403-1406.

104. Walensky, L.D., et al. 2004. Activation of apoptosis in vivo by a hydrocarbon-stapled $\mathrm{BH} 3$ helix. Science. 305:1466-1470.

105. Wang, J.L., et al. 2000. Structure-based discovery of an organic compound that binds Bcl- 2 protein and induces apoptosis of tumor cells. Proc. Natl. Acad. Sci. U. S. A. 97:7124-7129.

106. Enyedy, I.J., et al. 2001. Discovery of small-molecule inhibitors of Bcl-2 through structure-based computer screening. J. Med. Chem. 44:4313-4324.

107. Degterev, A., et al. 2001. Identification of smallmolecule inhibitors of interaction between the BH3 domain and Bcl-xL. Nat. Cell Biol. 3:173-182.

108.Nakashima, T., Miura, M., and Hara, M. 2000. Tetrocarcin A inhibits mitochondrial functions of Bcl-2 and suppresses its anti-apoptotic activity. Cancer Res. 60:1229-1235.

109. Tzung, S.P., et al. 2001. Antimycin A mimics a celldeath-inducing Bcl-2 homology domain 3. Nat. Cell Biol. 3:183-191.

110.Kim, K.M., et al. 2001. Biophysical characterization of recombinant human $\mathrm{Bcl}-2$ and its interactions with an inhibitory ligand, antimycin A. Biochemistry. 40:4911-4922.

111.Kutzki, O., et al. 2002. Development of a potent $\mathrm{Bcl}-\mathrm{x}(\mathrm{L})$ antagonist based on alpha-helix mimicry. J. Am. Chem. Soc. 124:11838-11839.

112.Leone, M., et al. 2003. Cancer prevention by tea polyphenols is linked to their direct inhibition of antiapoptotic Bcl-2-family proteins. Cancer Res. 63:8118-8121.

113. Kitada, S., et al. 2003. Discovery, characterization, and structure-activity relationships studies of proapoptotic polyphenols targeting B-cell lymphocyte/ leukemia-2 proteins. J. Med. Chem. 46:4259-4264.

114. Becattini, B., et al. 2004. Rational design and real time, in-cell detection of the proapoptotic activity of a novel compound targeting Bcl-X(L). Chem. Biol. 11:389-395.

115. Oltersdorf, T., et al. 2005. An inhibitor of Bcl-2 family proteins induces regression of solid tumours. Nature. 435:677-681.

116.Jansen, B., et al. 1998. bcl-2 antisense therapy chemosensitizes human melanoma in SCID mice. Nat. Med. 4:232-234.

117. Waters, J.S., et al. 2000. Phase I clinical and pharmacokinetic study of bcl-2 antisense oligonucleotide therapy in patients with non-Hodgkin's lymphoma. J. Clin. Oncol. 18:1812-1823.

118. Konopleva, M., et al. 2000. Liposomal Bcl-2 antisense oligonucleotides enhance proliferation, sensitize acute myeloid leukemia to cytosine-arabinoside, and induce apoptosis independent of other antiapoptotic proteins. Blood. 95:3929-3938.

119. Murthy, M.S., et al. 2001. A small molecule inhibitor of BCL-2 protein-protein interactions specifically induces apoptosis in cancer cells [abstract]. Clin. Cancer Res. 7:313. 